\title{
Rhodococcus equi virulento aislado de potrillos Fina Sangre de Carrera en Chile
}

\author{
Virulent Rhodococcus equi isolated from thoroughbred foals in Chile \\ Jorge C. Lohse ${ }^{1,2,5}$, Enrique Paredes ${ }^{2}$, Danilo Vargas ${ }^{3}$, Shinji Takai ${ }^{4}$
}

\section{Resumen}

El objetivo del presente estudio fue establecer el diagnóstico y aislado de variantes virulentas de la cepa Rhodococcus equi y su asociación con trastornos respiratorios, digestivos o de ambos en potrillos Fina Sangre de Carrera. Se obtuvo muestras de sangre de 86 ejemplares entre 1 y 6 meses de edad con presencia de signos clínicos respiratorios y digestivos entre 2006 y 2008 en nueve haras de la Región Metropolitana, Chile. Todas las muestras se procesaron y analizaron mediante PCR para detección de presencia de $R$. equi y sus proteínas asociadas a la virulencia (Vap) (A, C, D, E, F, G, H). El 41.9\% de los potrillos fueron positivos a $R$. equi. Los factores de virulencia detectados en potrillos con trastornos respiratorios fueron vapA, vapC y vapG en el $5.8 \%$ de la población muestreada, con valores de asociación de Spearman de $\mathrm{r}=0.885 ; \mathrm{r}=0.976 ; \mathrm{r}=0.885$, respectivamente. No se identificaron variantes virulentas de $R$. equi en los potrillos con signos clínicos digestivos.

Palabras clave: Rhodococcus equi; potros; Vap; bronconeumonía

\section{AbSTRACT}

The aim of this study was to establish the diagnosis and isolation of virulent variants of Rhodococcus equi strains and their association with respiratory and digestive disorders or both in Thoroughbred foals. Blood samples were collected from 86 foals ranging 1 to

\footnotetext{
${ }^{1}$ Escuela de Ciencias Veterinarias, Universidad Viña del Mar, Viña del Mar, Chile

${ }^{2}$ Instituto de Patología Animal, Facultad de Ciencias Veterinarias, Universidad Austral de Chile, Valdivia, Chile

${ }^{3}$ Facultad de Ciencias Agropecuarias, Escuela de Medicina Veterinaria, Universidad Pedro de Valdivia, Santiago, Chile

${ }^{4}$ School of Veterinary Medicine, Kitasato University, Towada, Aomori, Japan

${ }^{5}$ E-mail: lohse.j@gmail.com

El estudio fue financiado por FIDUM 1787 de la Universidad Mayor
}

Recibido: 19 de octubre de 2018

Aceptado para publicación: 29 de junio de 2019 
6 months of age with presence of respiratory and digestive clinical signs between 2006 and 2008 in nine farms of the Metropolitan Region, Chile. All samples were processed and analysed by PCR to detect the presence of $R$. equi and its virulence-associated proteins (Vap) (A, C, D, E, F, G, H). Results showed that $41.9 \%$ of the foals were positive to R. equi. The virulence factors detected in foals with respiratory disorders were vapA, vapC and $v a p G$ in $5.8 \%$ of the sampled population, with Spearman's association values of $\mathrm{r}=0.885$; $\mathrm{r}=0.976 ; \mathrm{r}=0.885$ respectively. No virulent variants of $R$.equi were identified in foals with digestive disorders.

Key words: Rhodococcus equi; foals; Vap; bronchopneumonia

\section{INTRODUCCIÓN}

Rodococosis es una enfermedad causada por Rhodococcus equi, que provoca bronconeumonía aguda o crónica y enteritis en potrillos, siendo una de las mayores causas de morbilidad y mortalidad en potrillos (Ainsworth et al.,1997; Sellon et al., 2000; Meijer y Prescott, 2004; Son et al., 2006; Chhabra et al., 2015; Gressler et al., 2018). $R$. equi es una bacteria facultativa grampositiva, pleomorfa y patógeno intracelular facultativo de macrófagos y habitante saprofito del suelo, aerobio estricto, con pocos requerimientos para su crecimiento y desarrollo (McQueen et al., 2015). La infección por $R$. equi también se describe en otras especies (Bertone, 1998), y en el humano se asocia a neumonías, mayormente en pacientes inmunocomprometidos (Byrne et al., 2001). Las principales vías de infección son la inhalación (partículas de polvo) y la ingestión del organismo (Hondalus, 1997; Leadon et al., 2007).

A diferencia de la mayoría de los R. equi aislados del medioambiente, aquellos aislados de potrillos con neumonía poseen un plásmido que codifica una proteína altamente inmunogénica y lipomodificada asociada a virulencia (Vap), (Takai et al., 2000; Byrne et al., 2001; Valero-Rello et al., 2015). El genoma de $R$. equi posee un total 5043170 $\mathrm{pb}$, contiene ADN cromosómico genéticamente estable y un plásmido de virulencia de $80 \mathrm{a} 90 \mathrm{~kb}$, que es el principal determinante de la patogenicidad (Letek et al., 2010; Giguère et al., 2011). La virulencia de R. equi se basa en la capacidad del organismo para replicarse en macrófagos, que depende de su capacidad para interferir con la maduración endosomal después de la fagocitosis y para prevenir la acidificación de la vacuola en la que reside (Hondalous y Mosser, 1994; Toyooka et al., 2005).

Este plásmido presenta una isla de patogenicidad adquirida (PAI), que le confiere capacidad de infectar macrófagos (Hondalus y Mosser, 1994; Giguère et al., 1999; Takai et al., 2000; Coulson et al., 2015). En vap PAI existe un conjunto de genes homólogos que codifican para una familia de proteínas de Vap asociados estrechamente, designados como $\operatorname{Vap} A, \operatorname{Vap} C$, VapD, VapE, Vap G, and VapH. También contiene un número de genes no-vap, en particular el operón vir albergando dos reguladores (virR y virS) que activan la expresión de la PAI (Byrne et al., 2001). Adicionalmente hay tres pseudogenes vapF, vapI and vapX. Se desconoce el rol de estos genes adicionales Vap y si codifican proteínas con funciones superpuestas o redundantes (Okoko et al., 2015). El vapA se considera esencial en la patogénesis de la rodococosis (ValeroRello et al., 2015) y se describe como una proteína inmunodominante en los aislados clínicos (Takai et al., 1991a,b; Tan et al., 1995).

Actualmente, muchos criaderos con alta prevalencia de neumonía por $R$. equi examinan a los potrillos utilizando técnicas como el 
recuento de glóbulos blancos, determinación de la concentración plasmática de fibrinógeno, radiografía y ultrasonido de tórax para poder detectar casos subclínicos (Giguère et al., 2003; Vener et al., 2012). El diagnóstico definitivo de rodococosis es a través del cultivo bacteriológico y la amplificación de los genes vap por la Reacción en Cadena de la Polimerasa (PCR) en aspirados traqueobronqueales (ATB) de potrillos con signos clínicos de tracto respiratorio inferior, o evidencia citológica de inflamación séptica de vías aéreas y/o evidencia radiológica o de ultrasonido de bronconeumonía (Sellon et al., 2001; Giguère et al., 2011).

El ensayo de PCR multiplex para la familia del gen de vap ha permitido la identificación y caracterización de aislados virulentos en una reacción simple en un solo paso (Chhabra et al., 2015). La formulación de una vacuna efectiva contra la infección por $R$. equi se encuentra aún en proceso. Actualmente, el uso de una vacuna oral viva ha generado resultados prometedores in vivo, al igual que vectores bacterianos en modelo murino (Dawson et al., 2010; Giles et al., 2015). La inmunidad celular mediada es considerada crucial para superar una infección causada por este patógeno (Giles et al., 2015).

En Chile se ha aislado la bacteria y se le ha diagnosticado por PCR en equinos (Paredes et al., 2000; Miranda, 2003; Márquez, 2006). El presente estudio tuvo como objetivo identificar cepas virulentas de $R$. equi mediante PCR, así como determinar la asociación entre cepas de variantes virulentas y signos clínicos respiratorios, digestivos o ambos en potrillos Fina Sangre de Carrera en la zona central de Chile.

\section{Materiales y Métodos}

Este estudio fue realizado entre los años 2006 y 2008 . Se colectaron muestras de sangre de 86 potrillos Fina Sangre de Carrera
(FSC), entre 1 y 6 meses de edad, pertenecientes a nueve haras de la Región Metropolitana, Chile. El criterio de inclusión fue la presencia de signos clínicos respiratorios, gastrointestinales o de ambos. Las muestras de sangre fueron obtenidas por punción de la vena yugular utilizando tubos EDTA $\mathrm{K}_{2}$ Vacutainer ${ }^{\circledR}$ y almacenadas a $4{ }^{\circ} \mathrm{C}$ hasta su procesamiento. La extracción de $\mathrm{ADN}$, a partir de muestras de sangre, se efectuó según lo descrito por Hoos y Paabo (1993). La cuantificación del ADN extraído de las bacterias se efectuó mediante un espectofotómetro (UV-VIS, Agilent Technologies ${ }^{\circledR}$ ), por absorción a 260 y $280 \mathrm{~nm}$, donde una unidad de densidad óptica equivale a $50 \mu \mathrm{g} / \mathrm{ml}$ de ADN de doble hebra (Sambroock et al., 1989). Para establecer el Índice de Pureza (IP) del ADN se utilizaron los cocientes de absorbancia (DO) a 260 y $280 \mathrm{~nm}$, según lo descrito por Sambrook et al. (1989): IP = DO a $260 \mathrm{~nm} / \mathrm{DO}$ a $280 \mathrm{~nm}$.

La mezcla de reacción que se utilizó en la identificación de $R$. equi desde muestras biológicas, es la descrita por Miranda (2003) y el programa de termociclado fue el descrito por Takai et al. (1995). La estandarización de PCR se efectuó según lo descrito por Miranda (2003). La resolución de los productos de amplificación (amplicones) se realizó por electroforesis en gel de agarosa $(1 \% \mathrm{p} / \mathrm{v})$ teñido con bromuro de etidio $(0.005 \mu \mathrm{g} / \mathrm{ml})$ en tampón de corrida TBE $(0.09 \mathrm{M}$ tris-borato; 0.002M EDTA, pH 8.0). La observación de las bandas de ADN amplificado se efectuó por medio de un transiluminador de luz ultravioleta ( 50 watts, Vilber Lourmat ${ }^{\circledR}$, Francia) y los resultados se registraron por fotografias con cámara Olympus ${ }^{\circledR} \mathrm{N}^{\circ} \mathrm{C}-5060$ para su posterior interpretación. La confirmación del genoma de $R$. equi se efectuó por purificación y posterior secuenciación del ADN amplificado.

Además, se utilizaron los cebadores empleados por Byrne et al. (2001) para $R$. equi obtenidos del plásmido virulento ATCC 33701 al igual que para la variante virulenta vapA. Los cebadores desde vapC al vapH 
Cuadro 1. Secuencia de cebadores utilizados en el estudio

\begin{tabular}{|c|c|c|}
\hline Bacteria-Vap & Cebador & Secuencia $\left(5^{\prime}-3^{\prime}\right)$ \\
\hline R. equi & DM.1 & TCG TCC GTG AAA ACT TGG G \\
\hline R. equi & DM.2 & CGA CCA CAA GGG GGC CGT \\
\hline R. equi $\mathrm{VapA}$ & $\mathrm{RX}-1$ & GAC TCT TCA CAA GAC GGT \\
\hline R. equi VapA & $\mathrm{RX}-2$ & TAG GCG TTG TGC CAG CTA \\
\hline R. equi $\mathrm{VapC}$ & VapC-1 & TCC AAA TCG ATA GCC GTT GT \\
\hline R. equi VapC & VapC-2 & ACC AAA TGC CAT CGC CCA TT \\
\hline R. equi VapD & VapD-1 & ATC GCA ACG GTC TCA ATG GGA \\
\hline R. equi $\mathrm{VapD}$ & VapD-2 & ATA CTG TCC CAG CAG CAC CA \\
\hline R. equi VapE & VapE-1 & TCC GAA AGG AGATTA ATA T \\
\hline R. equi VapE & VapE-2 & ATT TGG CAG GGT TAA ACT T \\
\hline R. equi $\mathrm{VapF}$ & VapF-1 & AAT ATG CCT GGT ATG GGC CGT \\
\hline R. equi VapF & VapF-2 & TGA ACA CTC CCA AGA ATG CCA \\
\hline R. equi $\mathrm{VapG}$ & VapG-1 & GAT GGA TCC AGA CTG CAC GT \\
\hline R. equi $\mathrm{VapG}$ & VapG-2 & TGA GTG TTC GGA CCC TTT TG \\
\hline R. equi $\mathrm{VapH}$ & VapH-1 & CGA AAG TTC CTA TCA AGG AC \\
\hline R. equi $\mathrm{VapH}$ & VapH-2 & ACC TCC GCC AAT ACC GAT TA \\
\hline
\end{tabular}

Se usaron los partidores empleados por Byrne et al. (2001) para R. equi obtenidos del plásmido virulento ATCC 33701, al igual que para la variante virulenta VapA. Los partidores desde VapCal VapH fueron realizado por Invitrogen ${ }^{\circledR}$ [secuencia enviada por Takai (2006)].

fueron preparados por la empresa Invitrogen (Cuadro 1). La cuantificación del ADN se efectuó según procedimiento descrito por Sambrook et al. (1989). El programa de termociclación que se utilizó es el descrito por Takai et al. (1999), con 30 ciclos de amplificación. Las condiciones cíclicas fueron: desnaturalización $90 \mathrm{~s} \mathrm{a} 94{ }^{\circ} \mathrm{C}$, hibridación 1 min a $55^{\circ} \mathrm{C}$ y extensión 2 min a $72{ }^{\circ} \mathrm{C}$.

La resolución de las muestras de $\mathrm{ADN}$ amplificadas se efectuó por cámara de electroforesis horizontal (Wide Mini-Sub ${ }^{\circledR}$, BIO-RAD) en gel de agarosa al $1 \% \mathrm{P} / \mathrm{V}$, teñido con bromuro de etidio ( $0.005 \%)$, según procedimiento estándar, utilizando como solución amortiguadora de corrida TBE $0.5 \mathrm{X}$ (0.09 M Tris-Borato, 0.002M EDTA pH 8.0). La resolución del amplicón característico de $R$. equi se efectuó por electroforesis en gel de agarosa $1 \% \mathrm{P} / \mathrm{V}$, según lo descrito por Sambrook et al. (1989), con marcadores de peso molecular Ladder de 100 pares de base (pb) Gybco BRL ${ }^{\circledR}$. Para el amplicón de 441 $\mathrm{pb}$ se utilizaron los cebadores descritos por Sellon et al. (2001).

\section{Análisis Estadístico}

Se realizó un análisis estadístico descriptivo. Los resultados se expresaron en porcentaje. El coeficiente de correlación de Spearman fue usado para determinar asociación entre rodococosis y los genes vap encontrados con el tipo de trastorno digestivo y/o respiratorio. Se utilizó el programa estadístico IBM SPSS ${ }^{\circledR}$ y un nivel de significancia de $p<0.05$. 


\section{Resultados}

Se colectaron muestras de 86 potrillos. De estos, 64 presentaron signos clínicos respiratorios, 17 con signos gastrointestinales y 5 con ambos tipos de signos clínicos. La mayoría de las muestras fueron tomadas durante la época de verano, en el mes de febrero (52\%). Las muestras de ADN promediaron una concentración de $133 \mathrm{ng} / \mu 1$, con un IP de 1.8.

Se encontraron 36 potrillos (41.9\%) positivos a $R$. equi, siendo $5.8 \%$ vapA $(5 / 86)$, $1.2 \% \operatorname{vapC}(1 / 86)$ y $5.8 \%$ vapG (5/86) (Figuras 1-3). Por otra parte, solo en $1.2 \%$ $(1 / 86)$ de las muestras se observó presencia de vapA, vapC y vapG, y en $4.6 \%(4 / 86)$ vapA y vap $G$. Los Vap D, E, F, H no fueron identificados en la población de estudio. Las muestras positivas a Vap se observaron únicamente en potrillos con signos clínicos respiratorios.

El coeficiente de correlación de Spearman entre vapA, vapC, vapG y signos clínicos de desordenes respiratorios fue de

$\mathrm{r}=0.885, \mathrm{r}=0.976$ y r $=0.885$, respectivamente; asociación alta y positiva que indica alta confiabilidad.

\section{Discusión}

Este estudio demuestra la presencia en Chile de variantes virulentas de $R$. equi en potrillos FSC con trastornos respiratorios en la zona central de Chile, siendo las variantes virulentas encontradas VapA, VapC y VapG. El $41.9 \%$ de los potrillos fue positivo a $R$. equi, porcentaje mayor del $35 \%$ encontrado por Miranda (2003) en una población de potrillos con y sin signos clínicos de tipo respiratorio y digestivo y del $33 \%$ reportado por Márquez (2006).

R. equi había sido reportado en el país mediante cultivo desde absceso pulmonar en un potrillo FSC (Paredes et al., 2000) y confirmado mediante PCR desde muestra de sangre y secreción nasofaríngea (Miranda, 2003). Así mismo, Marquez (2006) identificó una variante VapA por PCR desde mues-

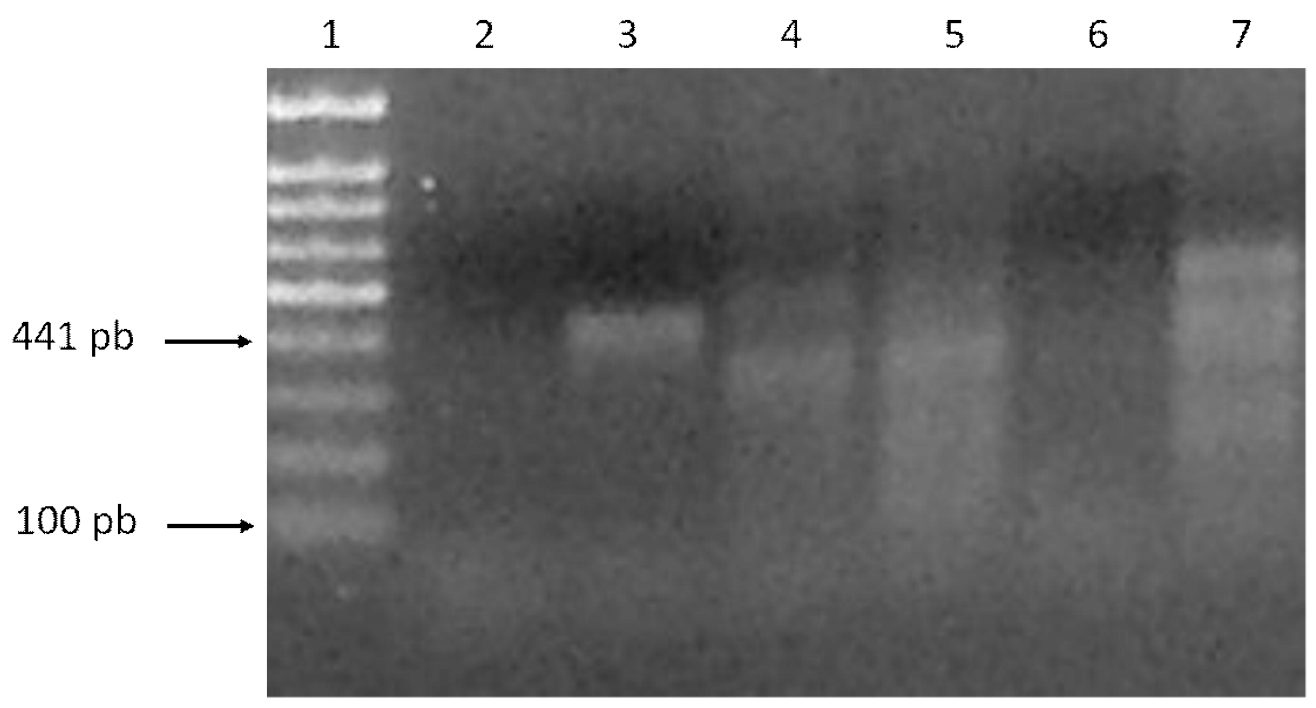

Figura 1. PCR en muestras de sangre de potrillos con signos clínicos respiratorios. Electroforesis en gel de agarosa al $1 \% \mathrm{p} / \mathrm{v}$ teñido con bromuro de etidio al $0.005 \%$. Carril 1: Ladder Gibco BRL ${ }^{\circledR}$. Indicador de peso molecular de $100 \mathrm{pb}$. Carril 2: Control negativo de amplificación (agua). Carril 3: 280 ng de ADN extraídos a partir de cepa ATCC 6939 (control positivo). Carriles 4, 5, 7: Muestras de sangre positiva a $R$. equi de potrillos. Carril 6: Muestra de sangre negativa a $R$. equi de potrillos. 


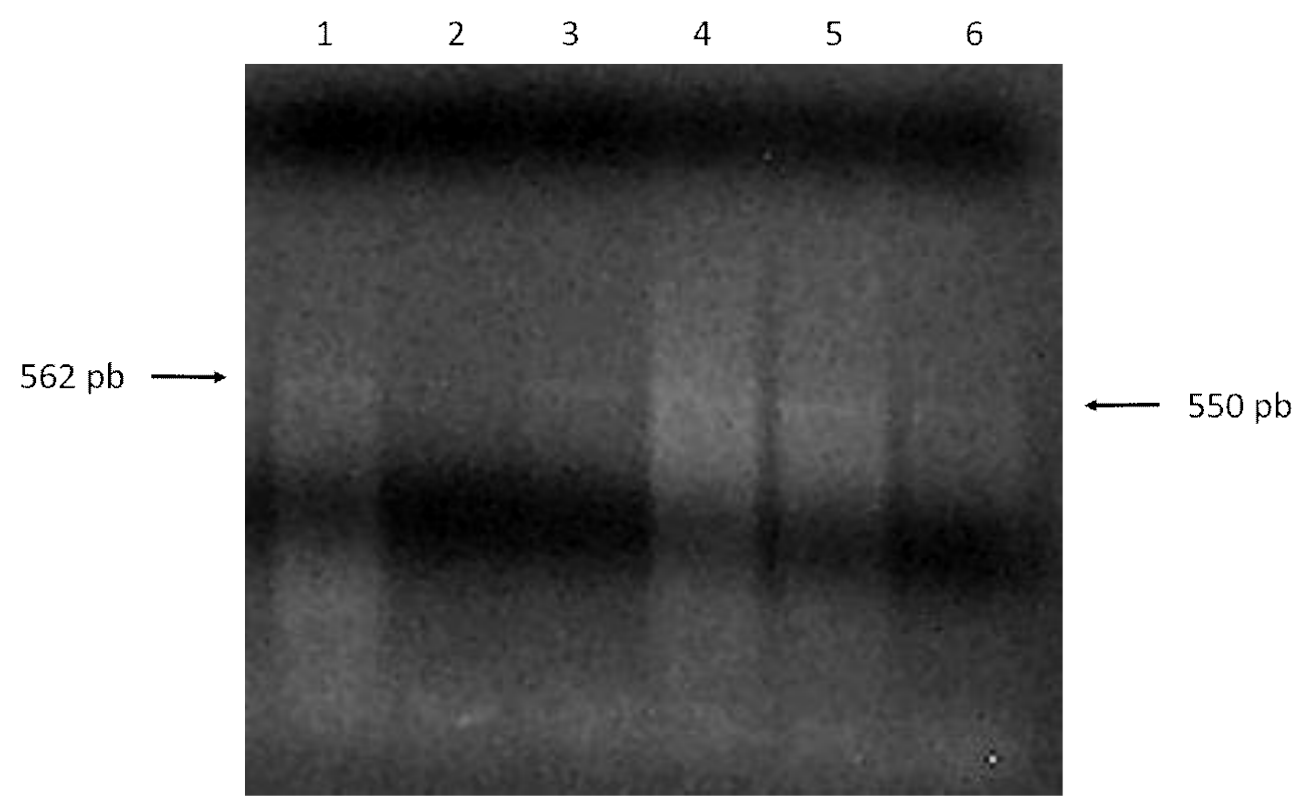

Figura 2. Aplicación de PCR para detectar VapA en muestras de sangre de potrillos con signos clínicos respiratorios. Electroforesis en gel de agarosa al $1 \% \mathrm{p} / \mathrm{v}$ teñido con bromuro de etidio al $0.005 \%$. Carril 1, 2: ADN procedente de muestra de sangre positiva a VapA de R. equi. Carril 3: Muestra de sangre negativa a VapA de R. equi. Carril 4, 5, 6: ADN procedente de muestra de sangre positiva a VapA de $R$. equi

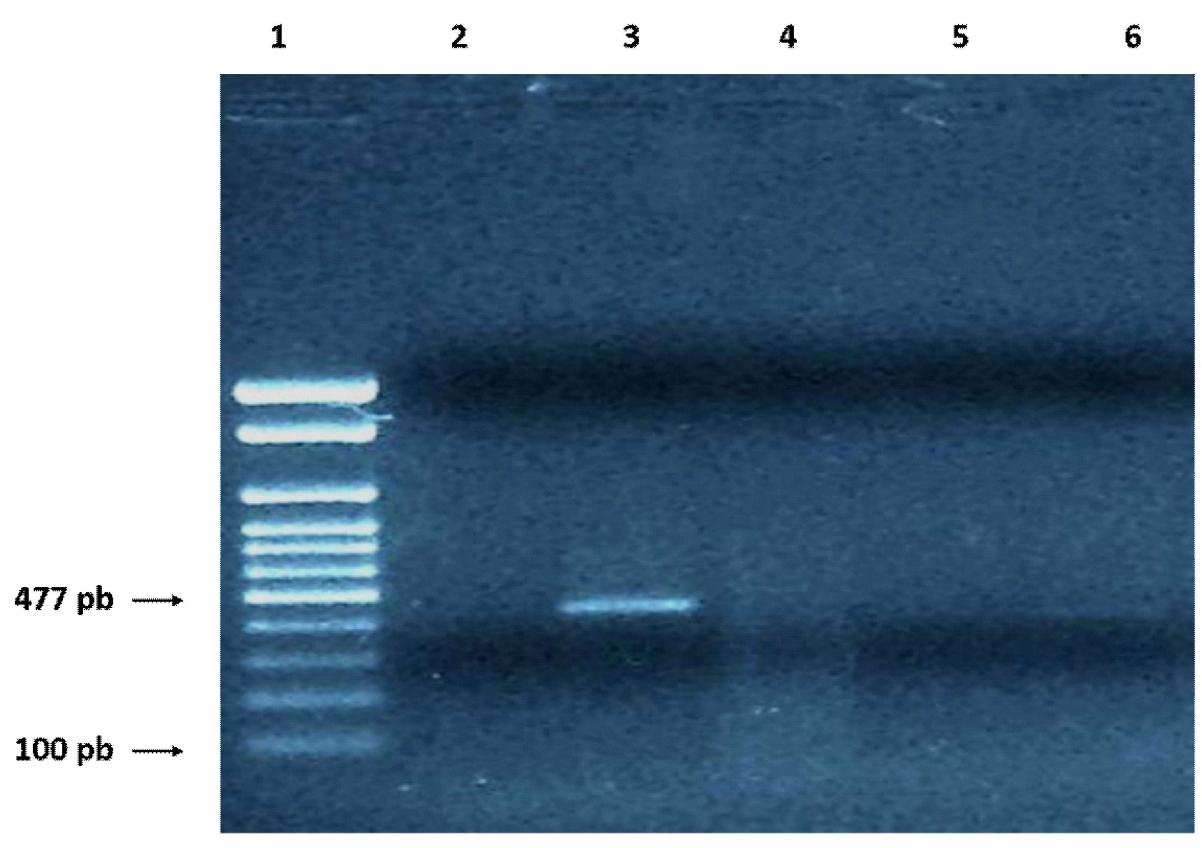

Figura 3. Aplicación de PCR para detectar VapC en muestras de sangre de potrillos con signos clínicos respiratorios. Electroforesis en gel de agarosa al 1\% p/v teñido con bromuro de etidio al $0.005 \%$. Carril 1: Ladder Gibco BRL®. Indicador de peso molecular de 100 pb. Carril 2: Control negativo de amplificación (agua). Carril 3: 280 ng de ADN extraídos de la cepa ATCC 6939 (control positivo). Carril 4, 5: Muestra de sangre negativa a VapC de $R$. equi. Carril 6: ADN procedente de muestra de sangre positiva a VapC de R. equi 
tra sanguínea en potrillos FSC clínicamente sanos. Gressler et al. (2018) también identificaron $R$. equi en cavidad nasal mediante la técnica PCR múltiple en equinos clínicamente sanos, indicando que está presente como parte de la flora bacteriana normal de la cavidad nasal en ejemplares criados en pasturas.

Los ejemplares positivos a Vap presentaron edades entre 3 y 4 meses de edad, rango etario en que la concentración de anticuerpos disminuye y, por lo tanto, los potrillos son más susceptibles a contraer la enfermedad (Vivrette, 1992). Los resultados encontrados de acuerdo con la época del año coinciden con Meijer y Prescott (2004), quienes mencionan como factores predisponentes a los ambientes calurosos, secos, polvorientos. En este estudio, las muestras fueron obtenidas de criaderos que poseen una alta densidad de población equina, lo que concuerda con lo descrito por Chaffin et al. (2003), quienes correlacionan positivamente densidad poblacional con $R$. equi patógeno.

La asociación obtenida en este estudio de potrillos con R. equi con variantes VapA, $\operatorname{Vap} C$ y $\operatorname{Vap} G$ con signos clínicos respiratorios fue significativa y positiva y de alta confiabilidad, no encontrando Vap en potrillos con trastornos gastrointestinales. Se describe que puede existir trastornos extrapulmonares en potros con neumonía por $R$. equi, encontrándose hasta un $74 \%$ de potros afectados (Johns, 2013). Estos trastornos pueden ser: artritis séptica, osteomielitis, absceso abdominal o colitis, o como consecuencia de una reacción inmune mediada, uveítis, sinovitis no séptica (típicamente de articulaciones múltiples), y anemia hemolítica inmuno mediada.

El plásmido de virulencia de $R$. equi ha sido reconocido por su asociación con la enfermedad causada por esta bacteria, y el plásmido VapA se indica como factor primario determinante en la virulencia de rodococosis (Okoko et al., 2015; Valero-Rello et al., 2015). Makrai et al. (2002) mostraron que el $88 \%$ de los aislamientos de $R$. equi en potros tienen VapA.
Se ha descrito que el cultivo microbiológico de muestras obtenida por ATB ha sido utilizado para el diagnóstico clínico de neumonía causada por R. equi, pero su sensibilidad es baja y se describen falsos negativos (Sweeney et al., 1987; Woolcock et al., 1987). El análisis de sangre e imagenología también se usan para loa diagnósticos presuntivos clínicos (Giguère et al., 2011). El diagnóstico serológico ha sido propuesto, pero con limitaciones (Arriaga et al., 2002). La técnica de PCR no solo es aplicable a secreciones de ATB, sino también a muestras de sangre (Bell et al., 1996; Sellon et al., 1997), saliva o exudados, evitando de esta manera el empleo de cultivos bacteriológicos (Bell et al., 1996). Se han estudiado otros métodos como el PCR cuantitativo en tiempo real (qPCR) en muestras fecales para el diagnóstico temprano de neumonía en potrillos con R. equi (Madrigal et al., 2016); sin embargo, debe evaluarse la posibilidad de extrapolar resultados de estos análisis a otras poblaciones (Shaw et al., 2015).

\section{Literatura Citada}

1. Ainsworth DM, Yeagar AM, Eicker SW, Erb HE, Davidow E. 1997. Athletic performance of horses previously infected with $R$. equi pneumonia as foal. P Annu Conv Am Equin 43: 81-82.

2. Arriaga JM, Cohen ND, Derr JN, Chaffin MK, Martens RJ. 2002. Detection of Rhodococcus equi by polymerase chain reaction using speciesspecific nonproprietary primers. J Vet Diagn Invest 14: 347-353. doi: 10.1177/ 104063870201400416

3. Bell KS, Philp JC, Christofi N, Aw DW. 1996. Identification of Rhodococcus equi using the polymerase chain reaction. Lett Appl Microbiol 23: 72-74. doi: 10.1111/j.1472-765X.1996.tb00033.x

4. Bertone J. 1998. Pneumonia and other disorders associated with Rhodococcus equi. In: Reed S, Bayly W (eds). Equine internal medicine. $2^{\text {nd }}$ ed. Philadelphia: Saunders. p 970-978. 
5. Byrne BA, Prescott JF, GH Palmer, Takai S, Nicholson V, Alperin DC, Hines S. 2001. Virulence plasmid of Rhodococcus equi contains inducible gene family encoding secreted proteins. Infect Immun 69: 650-656. doi: 10.1128/ IAI.69.2.650-656.2001

6. Chaffin MK, Cohen ND, Martens RJ. 2003. Evaluation of equine breeding farm characteristics as risk factors for development of Rhodococcus equi pneumonia in foals. J Am Vet Med Assoc 222: 467-475.

7. Chhabra S, Khurana SK, Kapoor PK, Singha H, Singh Y, Khirbat R. 2015. Characterization of Rhodococcus equi isolates from foals with respiratory problems using a multiplex PCR for the vap Genes. Adv Anim Vet Sci 3: 28-32. doi: 10.14737/journal.aavs/2015/3.1s.28.32

8. Coulson GB, Miranda-CasoLuengo AA, Miranda-Caso Luengo $R$, Wang $X$, Oliver J, Willingham-Lane JM, Meijer WG, et al. 2015. Transcriptome reprogramming by plasmid-encoded transcriptional regulators is required for host niche adaption of a macrophage pathogen. Infect Immun 83: 3137-3145. doi: 10.1128/IAI.00230-15

9. Dawson TR, Horohov DW, Meijer WG, Muscatello G 2010. Current understanding of the equine immune response to Rhodococcus equi. An immunological review of $R$. equi pneumonia. Vet Immunol Immunop 135: 1-11. doi: 10.1016/j.vetimm.2009.12.004

10. Giguère S, Hernandez J, Gaskin JM, Miller C, Bowman JL. 2003. Evaluation of WBC concentration, plasma fibrinogen concentration, and an agar gel immunodiffusion test for early identification of foals with Rhodococcus equi pneumonia. J Am Vet Med Assoc 222: 775-781. doi: 10.2460/javma.2003.222.775

11. Giguère S, Hondalus MK, Yager JA, Darrah P, Mosser DM, Prescott JF. 1999. Role of the 85-kilobase plasmid and plasmid-encoded virulence-associa- ted protein A in intracellular survival and virulence of Rhodococcus equi. Infect Immun 67: 3548-3557.

12. Giguère S, Cohen ND, Chaffin MK, Hines SA, Hondalus MK, Prescott JF, Slovis NM. 2011. Rhodococcus equi: clinical manifestations, virulence, and immunity. J Vet Intern Med 25: 1221 1230. doi: 10.1111/j.1939-1676.2011.00804.X

13. Giles C, Vanniasinkam T, Ndi S, Barton MD. 2015. Rhodococcus equi (Prescottella equi) vaccines; the future of vaccine development. Equine Vet J 47: 510-518. doi: 10.1111/evj.12310

14. Gressler LT, Machado G, da Silveira BP, Cohen ND, Corbellini LG, Leotti VB, Diehl GN, et al. 2018. Prevalence of Rhodococcus equi from the nasal cavity of 1010 apparently healthy horses. Equine Vet J 50: 667-671. doi: 10.1111/evj.12804

15. Hondalus MK. 1997. Rhodococcus equi: pathogenesis and virulence. In: XLIII Annual Convention Proceedings of American Association of Equine Practitioners. USA.

16. Hondalus MK, Mosser DM. 1994. Survival and replication of Rhodococcus equi in macrophages. Infect Immun 62: 4167-4175.

17. Hoos M, Paabo S. 1993. DNA extraction from pleistocene bones by a silica-based purification method. Nucleic Acids Res. 21:3913-3914. doi: 10.1093/nar/21.16.3913

18. Johns IC, Desrochers A, Wotman KL, Sweeney $R W$. 2011. Presumed immunemediated hemolytic anemia in two foals with Rhodococcus equi infec-tion. J Vet Emerg Crit Care. 21:273-278. doi: 10.1111/ j.1476-4431.2011.00633.x

19. Johns I. 2013. Management of Rhodococcus equi pneumonia in foals. Vet Med Res Rep 4: 49-59. doi: 10.2147/ VMRR.S39716

20. Leadon DP, Klay M, Buckley T, Fogarty $U$, Lewis AD, Vazquez-Boland JA. 2007. A review of foal pneumonias with an assessment of the importance of $R$. equi. Satellite Meeting of the World Equine Veterinary Association. Valdivia, Chile. 
21. Letek M, Gonzalez P, Macarthur I, Rodriguez H, Freeman TC, ValeroRello A, Blanco M, et al. 2010. The genome of a pathogenic Rhodococcus: cooptive virulence underpinned by key gene acquisitions. PLoS Genet 6(9): e1001145. doi: 0.1371/journal.pgen.1001145

22. Madrigal RG, Shaw SD, Witkowski LA, Sisson BE, Blodgett GP, Chaffin MK, Cohen ND. 2016. Use of serial quantitative PCR of the vapA gene of Rhodococcus equi in feces for early detection of $R$. equi pneumonia in foals. $\mathrm{J}$ Vet Intern Med 30: 664-670. doi: 10.1111/jvim. 13828

23. Makrai L, Takai S, Tamura M, Tsukamoto A, Sekimoto R, Sasaki Y, Kakuda T, et al. 2002. Characterization of virulence plasmid types in Rhodococcus equi isolates from foals, pigs, humans and soil in Hungary. Vet Microbiol 88: 377-384.

24. Márquez K. 2006. Estudio de la incidencia de Rodococosis equine y su relación con variantes génicas virulentas del agente etiológico en potrillos FSC en haras de la zona central de Chile. Tesis de Médico Veterinario. Santiago: Univ. Mayor. $60 \mathrm{p}$.

25. McQueen CM, Dindot SV, Foster MJ, Cohen ND. 2015. Genetic susceptibility to Rhodococcus equi. J Vet Intern Med 29: 1648-1659. doi: 10.1111/jvim. 13616

26. Meijer WG, Prescott JF. 2004. Rhodococcus equi. Vet Res 35: 383396. doi: 10.1051/vetres:2004024

27. Miranda DA. 2003. Identificación genómica de Rhodococcus equi a partir de muestras biológicas procedentes de equinos FSC de la zona central de Chile. Tesis de Médico Veterinario. Santiago: Univ. Mayor. $68 \mathrm{p}$.

28. Okoko T, Blagova EV, Whittingham JL, Dover LG, Wilkinsonb A. 2015. Structural characterisation of the virulence-associated protein VapG from the horse pathogen Rhodococcus equi. Vet Microbiol 31: 42-52. doi: 10.1016/ j.vetmic.2015.01.027
29. Paredes E, Gallego R, Canal AM, Araya O, Chahuán E, Thomas $P$, Zamora J. 2000. Primer caso descrito en Chile de neumonía y colitis por Rhodococcus equi en un potrillo. Arch Med Vet 32: 101-106. doi: 10.4067/ S0301-732X2000000100013

30. Sambrook J, Fritsch EF, Maniatis T. 1989. Molecular cloning: a laboratory manual. $2^{\text {nd }}$ ed. New York: Cold Spring Harbor Laboratory Press. 1546 p.

31. Sellon DC, Walket K, Suyemoto M, Altier C. 1997. Nucleic acid amplification for rapid detection of Rhodococcus equi in equine blood and tracheal wash fluids. Am J Vet Res 58: 12321237.

32. Sellon D, McConnico RS, Vivrette S. 2000. Diagnosis of Rhodococcus equi pneumonia in foals: PCR or culture? $\mathrm{P}$ Annu Conv Am Equin 46: 268-269.

33. Sellon DC, Besser TE, Vivrette SL, McConnico RS. 2001. Comparison of nucleic acid amplification, serology, and microbiologic culture for diagnosis of Rhodococcus equi pneumonia in foals. J Clin Microbiol 39: 1289-1293. doi: 10.1128/JCM.39.4.1289-1293.2001

34. Shaw SD, Cohen ND, Chaffin MK, Blodgett GP, Syndergaard M, Hurych D. 2015. Estimating the sensitivity and specificity of real time quantitative PCR of fecal samples for diagnosis of Rhodococcus equi pneumonia in foals. J Vet Intern Med 29: 1712-1717. doi: 10.1111/ jvim. 13631

35. Son W, Lee D, Yamatoda N, Hatori F, Shimizu N, Kakuda T, Sasaki Y, et al. 2006. Molecular typing of VapA-positive Rhodococcus equi isolates from Jeju native horses, Korea. J Vet Med Sci 68: 249-153.

36. Sweeney CR, Sweeney RW, Divers TJ. 1987. Rhodococcus equi pneumonia in 48 foals: response to antimicrobial therapy. Vet Microbiol 14: 329-336. doi: 10.1016/0378-1135(87)90120-9

37. Tan C, Prescott JF, Patterson MC, Nicholson VM. 1995. Molecular characterization of a lipid-modified 
virulence-associated protein of Rhodococcus equi and its potential in protective immunity. Can J Vet Res 59: 51-59.

38. Takai S, Koike K, Ohbushi S, Izumi C, Tsubaki S. 1991a. Identification of 15- to 17-kilodalton antigens associated with virulent Rhodococcus equi. J Clin Microbiol 29: 439-443.

39. Takai S, Sekizaki T, Ozawa T, Sugawara T, Watanabe Y, Tsubaki S. 1991b. Association between a large plasmid and 15- to 17-kilodalton antigens in virulent Rhodococcus equi. Infect Immun 59: 4056-4060.

40. Takai S, Ikeda T, Sasaki Y, Watanabe Y, Ozawa T, Tsubaki S, Sekizaki T. 1995. Identification of virulent Rhodococcus equi by amplification of gene coding 15-to 17- Kilodalton antigens. J Clin Microbiol 33: 1624-1627.

41. Takai S, Shoda M, Sasaki Y, Tsubaki S, Fortier G, Pronost S, Rahal K, et al. 1999. Restriction fragment length polymorphisms of virulence plasmids in Rhodococcus equi. J Clin Microbiol. 37: 3417-3420.

42. Takai S, Anzai T, Fujita Y, Akit O, Shoda M, Tsubaki S, Wada R. 2000. Pathogenicity of Rhodococcus equi expressing a virulence-associated $20 \mathrm{kDa}$ protein $(\operatorname{Vap} B)$ in foals. Vet Microbiol 76: 71-80. doi: 10.1016/S0378-1135(00)00226-1

43. Toyooka K, Takai S, Kirikae T. 2005. Rhodococcus equi can survive a phagolysosomal environment in macrophages by suppressing acidification of the phagolysosome. J Med Microbiol 2005: 1007-1015. doi: 10.1099/jmm.0.46086-0

44. Valero-Rello A, Hapeshi A, Anastasi E, Alvarez S, Scorttia M, Meijer WG, et al. 2015. An invertron-like linear plasmid mediates intracellular survival and virulence in bovine isolates of Rhodococcus equi. Infect Immun 83: 2725-2737. doi: 10.1128/IAI.00376-15

45. Venner $M$, Rödiger A, Laemmer $M$, Giguère S. 2012. Failure of antimi-crobial therapy to accelerate sponta-neous healing of subclinical pulmonary abscesses on a farm with endemic infections caused by Rhodococcus equi. Vet J 192: 293-298. doi: 10.1016/j.tvj1.2011.07.004

46. Vivrette S. 1992. The diagnosis, treatment, and prevention of Rhodoco-ccus equi pneumonia in foals. Vet Med 87: 144-149.

47. Woolcock JB, Mutimer NM, Bowles PM. 1987. The immunological response of foals to Rhodococcus equi: a review. Vet Microbiol 14: 215-224. 